\title{
Phenotype and genotype variation in primary carnitine deficiency
}

Yuhuan Wang, $M S^{1}$, Stanley H. Korman, $M B B S^{2}$, Jing Ye, $M D^{1}$, J. Jay Gargus, MD, PhD $D^{3}$, Alisa Gutman, $M D, P h D^{2}$, Franco Taroni, $\mathrm{MD}^{4}$, Barbara Garavaglia, $\mathrm{PhD}^{4}$, and Nicola Longo, $\mathrm{MD}, \mathrm{PhD} \mathrm{D}^{1}$

\begin{abstract}
Purpose: Primary carnitine deficiency is an autosomal recessive disorder of fatty acid oxidation resulting from defective carnitine transport. This disease is caused by mutations in the carnitine transporter gene SLC22A5. The objective of this study was to extend mutational analysis to four additional families with this disorder and determine whether recurrent mutations could be found. Methods: The SLC22A5 gene encoding the OCTN2 carnitine transporter was sequenced, and the missense mutations identified were expressed in Chinese hamster ovary (CHO) cells. Results: DNA sequencing revealed four novel mutations (Y4X; dup 254-264, 133X; R19P; R399Q). Alleles introducing premature STOP codons reduced the levels of OCTN2 mRNA. Carnitine transport in CHO cells expressing the R19P and R399Q mutations was reduced to $<5 \%$ of normal. The 133X mutation was found in two unrelated European families. Two patients within the same family, both homozygous for the same mutation (R399Q) had completely different clinical presentation. Conclusions: Heterogeneous mutations in the SLC22A5 gene cause primary carnitine deficiency. Different presentations are observed even in children with identical mutations. Genet Med 2001:3(6):387-392.
\end{abstract}

Key Words: carnitine deficiency, fatty acid oxidation, cardiomyopathy, developmental delay, OCTN2

Primary carnitine deficiency (OMIM: 212140) is an autosomal recessive disorder of fatty acid oxidation caused by defective carnitine transport. ${ }^{1}$ Carnitine is essential for the transfer of long-chain fatty acids from the cytosol to mitochondria for subsequent beta oxidation. The lack of carnitine impairs the ability to use fat as fuel during periods of fasting or stress. This condition can result in an acute metabolic decompensation early in life with hypoketotic hypoglycemia, Reye syndrome, and sudden infant death, or in a more insidious presentation, later in life, with skeletal or cardiac myopathy. The clinical disease can be prevented if the diagnosis is established early and the patient is started on adequate carnitine supplements. ${ }^{1}$ Recent studies indicate that many of these patients are likely to be missed by newborn screening programs using electrospray tandem mass spectrometry (MS/MS) for the measurement of free carnitine. ${ }^{2}$ A screening based on the identification of the molecular, rather than biochemical, defect would be ideal.

The gene for primary carnitine deficiency, SLC22A5, maps to chromosome $5 \mathrm{q} 31$ and encodes a novel organic cation transporter OCTN2 (OMIM: 603377). ${ }^{3,4}$ Different mutations in the SLC22A5 gene have been identified in patients with pri-

From the ${ }^{1}$ Division of Medical Genetics, Department of Pediatrics, Emory University, Atlanta, Georgia; ${ }^{2}$ Department of Clinical Biochemistry, Hadassah University Hospital, Jerusalem, Israel; ${ }^{3}$ Department of Physiology \& Biophysics and Section of Human Genetics, Department of Pediatrics, University of California, Irvine, California; and ${ }^{4}$ Divisione di Biochimica e Genetica, Istituto Nazionale Neurologico "C. Besta," Milan, Italy.

Nicola Longo, MD, PhD, Division of Medical Genetics, Department of Pediatrics, University of Utah, Room 2C412, SOM, 50 North Medical Drive, Salt Lake City, UT 84132.

Received: June 28, 2001.

Accepted: September 6, 2001. mary carnitine deficiency. ${ }^{5-14}$ These mutations define functional domains of the transporter important for carnitine recognition and energization by sodium, ${ }^{15}$ in addition to allowing precise diagnosis within affected families. In most cases, families have private mutations. However, in a few cases, the same mutation was found in unrelated patients. ${ }^{6,8,9,12}$ If a small group of mutations were responsible for the disease in a defined population, their identification could lead to a timely diagnosis. However, the number of families with carnitine deficiency studied at the molecular levels is still small, and it is unclear whether direct DNA analysis would be feasible.

To address this point, we extend mutational analysis of OCTN2 to four additional families with primary carnitine deficiency. These new families expand the spectrum of phenotypic variability in primary carnitine deficiency and clearly demonstrate that patients with identical mutations can have different age of onset and type of presentation. The additional variations in the DNA sequence identified in this study also indicate that several different mutations are present in defined geographic areas, rendering DNA analysis difficult to pursue for screening purposes.

\section{MATERIALS AND METHODS}

\section{Patients}

Patient 268 is a Swiss boy diagnosed with cardiomyopathy at 3 years of age after presenting with weakness and respiratory distress. Total carnitine in plasma was $<3 \mu \mathrm{M}$. He was placed on replacement therapy with resolution of the clinical picture. There was no known consanguinity. 
Patient 909 is an Italian boy who presented at 2 years of age with cardiomyopathy. His initial free carnitine was $1.7 \mu \mathrm{M}$, with an acylated carnitine of $1 \mu \mathrm{M}$. A muscle biopsy performed at time of presentation indicated low levels of free carnitine $(<0.01$, normal $16 \pm 3 \mathrm{nmol} / \mathrm{mg}$ of noncollagen protein). He was started on carnitine with reversal of the symptoms. He is currently developing and growing well at 12 years of age. His parents are unrelated.

Jer-T is a Jewish girl of Iranian descent who presented at 2 years of age in coma during an episode of gastroenteritis with vomiting and diarrhea. She had moderate hepatomegaly (liver enlarged to $4 \mathrm{~cm}$ below the right costal margin) and was hypoglycemic (glucose, $0.6 \mathrm{mM}-11 \mathrm{mg} / \mathrm{dL}$ ). She received intravenous glucose and recovered within 24 hours. At the time of hypoglycemia, plasma free fatty acids were $2.2 \mathrm{mM}, \beta$-hydroxybutyrate was $1.66 \mathrm{mM}$, and acetoacetate was $0.7 \mathrm{mM}$. Plasma urea was $13.5 \mathrm{mM}$ (normal, 3.3-6.5 mM), consistent with mild dehydration. CPK $(365 \mathrm{IU} / \mathrm{mL}$; normal range, 0-170) and liver enzymes (SGOT, $148 \mathrm{IU} / \mathrm{mL}$; normal, 2-60; SGPT, 59 IU/mL; normal, 6-53) were mildly elevated and normalized within 48 hours. Plasma lactate, pyruvate, and ammonia were normal. Urine organic acid analysis by gas chromatography/mass spectrometry (GC/MS) on a sample taken after the hypoglycemic episode was normal. Three days after admission, she underwent a fasting test (20 hours), which was uneventful. Plasma carnitine was extremely low (free $=1.1-1.3$ $\mu \mathrm{M}$, total $=1.7-2.1 \mu \mathrm{M}$ on separate occasions), with inappropriate urinary excretion of carnitine (free, 21.3; total, 26.8 $\mu \mathrm{mol} / \mathrm{mmol}$ creatinine). MS/MS analysis of acylcarnitines confirmed the deficiency of free carnitine and revealed a virtual absence of all acylcarnitine species apart from acetylcarnitine. Oral carnitine treatment $(100 \mathrm{mg} / \mathrm{kg}$ per day) increased plasma carnitine levels (free, 21.3-21.8 $\mu \mathrm{M}$; total, 26.8-37.9 $\mu \mathrm{M}$ ) and prevented further episodes of hypoglycemia.

Further inquiry revealed that the 4-year-old sister (Jer-H) had weakness of the proximal limb girdle musculature, requiring physical therapy, and developmental delays, involving language skills, concentration, and attention span. She was receiving physical and occupational therapy and attended a special education preschool program. She had previously undergone echocardiography for a systolic heart murmur, due to mild mitral valve regurgitation. Left ventricular size and function was normal. She also had extremely low levels of plasma carnitine (free, $1.7-2.9 \mu \mathrm{M}$; total, 2.4-3.2 $\mu \mathrm{M}$ ) with inappropriately high urinary carnitine excretion (free 12.1, total $13.6 \mu \mathrm{mol} /$ mol creatinine). She was also started on carnitine with a marked improvement of the muscle tone, general mood, alertness, activity, and concentration span. The parents are first cousins. Both have plasma carnitine levels in the lower range of normal (free, 32.9; total, $40.3 \mu \mathrm{M}$ for the father; free, 35.2; total, $42.3 \mu \mathrm{M}$ for the mother, normal range in adults free, 28-47 $\mu \mathrm{M}$; total, 37-58 $\mu \mathrm{M})$. They have a normal male child with normal plasma carnitine levels (free, 41.2; total, $52.1 \mu \mathrm{M}$ ). The mother has two additional children from a previous marriage (her former husband was not related to her). These two children are phenotypically normal (carnitine levels were not measured).

Patient JGSQ is a 4-year-old Pakistani female who presented at 6 months of age in coma after a 2-day history of intermittent low-grade fever. She was completely unresponsive with no corneal reflexes, and her liver was enlarged to approximately $4 \mathrm{~cm}$ below the costal margin. Blood glucose was low at $1.1 \mathrm{mM}$ (20 $\mathrm{mg} / \mathrm{dL}$ ), ammonia was elevated at $149 \mu \mathrm{M}$. Liver function tests, PT and PTT were mildly increased. Urine analysis indicated traces of ketones. She was given intravenous glucose and responded well, becoming alert the next day. A liver biopsy indicated microvesicular steatosis and glycogen accumulation. Urine organic acids indicated dicarboxylic aciduria. An acylcarnitine profile had no detectable peaks. She was started on carnitine (100 mg/kg per day), which normalized free carnitine levels and the acylcarnitine profile. Carnitine requirements increased over time, and she currently requires $450 \mathrm{mg} / \mathrm{kg}$ per day. She has had no additional episodes of significant decompensation. At 4 years of age, she has normal growth and her development is on target. The parents are very closely related, because two of the grand parents are siblings and the other two are aunt and nephew. The couple had an older son who was hospitalized at 5 months of age with dehydration. He responded to intravenous fluids with glucose and was discharged from the hospital. He died at 7 months of age in Pakistan during a subsequent episode. The couple also has a healthy boy and a healthy girl, who was diagnosed at birth as heterozygous for primary carnitine deficiency by measurement of carnitine transport in her fibroblasts.

\section{Cell strains and carnitine transport}

Fibroblasts from Patients 268, 909, Jer-T, Jer-H, and JGSQ with primary carnitine deficiency were obtained by skin biopsy for diagnostic purposes. Fibroblasts from other patients with primary carnitine deficiency were obtained as previously described. ${ }^{6,11,12,16}$ They were grown in Dulbecco-modified MEM supplemented with $15 \%$ fetal bovine serum. Chinese hamster ovary $(\mathrm{CHO})$ cells were grown in Ham F12 medium supplemented with $6 \%$ fetal bovine serum. Carnitine $(0.5 \mu \mathrm{M})$ transport was measured at $37^{\circ} \mathrm{C}$ as described previously. ${ }^{6,11,12,15}$ Nonsaturable carnitine transport was measured in the presence of $2 \mathrm{mM}$ cold carnitine and was subtracted from total transport to obtain saturable transport. Values are reported as means \pm SE of three to six independent determinations.

\section{DNA analysis and molecular techniques}

Genomic DNA was extracted from fibroblasts or peripheral blood by standard methods and amplified using polymerase chain reaction (PCR) and primers flanking each of the $10 \mathrm{ex}-$ ons. ${ }^{11}$ The primers used for exon 1 were $5^{\prime}$-TGCGCCATATGTAAGGCCAG-3' and 5'-ATCTGGGAGAGAGGAGCTC- 3 '. Mutations were confirmed by restriction analysis of independent PCR products. The mammalian expression vector with the green fluorescent protein fused to the C-terminus of OCTN2 was generated as previously described. ${ }^{15}$ Mutations were introduced by site-directed mutagenesis using the Quik 
Change system (Stratagene, La Jolla, CA) following the manufacturer's instructions. The final clones were sequenced to confirm the presence of the mutation and the absence of PCR artifacts. The clones were transfected into $\mathrm{CHO}$ cells using lipofectamine. ${ }^{6,15}$ Cells were selected for 2 weeks in $0.8 \mathrm{mg} / \mathrm{mL}$ of G418 and then used for the transport assay. Expression of the transgene was verified by the presence of green fluorescent protein detected by fluorescence microscopy. ${ }^{15}$ Northern blot analysis and mRNA quantitation were performed on human fibroblasts as previously described. ${ }^{6,15}$

\section{RESULTS}

\section{Carnitine transport and mutations in the SLC22A5 gene in patients with primary carnitine deficiency}

Carnitine transport was reduced to $<5 \%$ of controls in fibroblasts from Patients 268, 909, Jer-T, and Jer-H, in the range measured in cells from other patients with primary carnitine deficiency (Fig. 1). DNA was isolated from fibroblast cultures, and the 10 exons of the SLC22A5 gene were sequenced. Patient 268 was homozygous for a duplication of nucleotides 254-264 (11 nucleotides) in exon 1 (Fig. 2B). This duplication created a frameshift and resulted in the premature insertion of a STOP codon in position 133 of the predicted cDNA (133X). This duplication did not result in the loss or gain of any restriction site. However, upon digestion of exon 1 with HaeII, it produced a larger band of $112 \mathrm{bp}$, instead of the normal 101-bp band (Fig. 2A). Disappearance of the 101-bp band could not be appreciated due to the presence of an overlapping 102-bp band.

Patient 909 was heterozygous for the 11-bp duplication reported in Patient 268 and for a 56G $>C$ transversion converting the codon for arginine 19 to proline (R19P, CGC $>$ CCC). This mutation abolished an HaeII restriction site from exon 1,

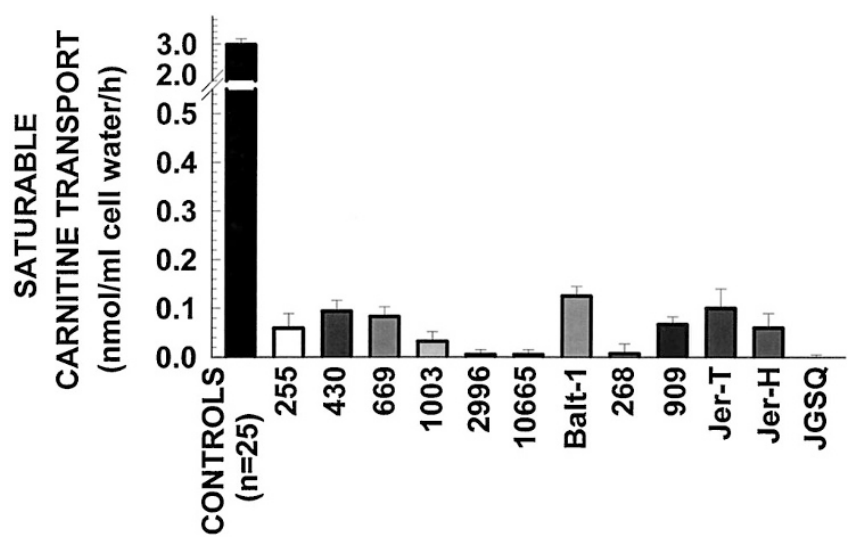

Fig. 1. Carnitine transport by fibroblasts obtained from patients with primary carnitine deficiency. Carnitine $(0.5 \mu \mathrm{M})$ transport was measured for 4 hours at $37^{\circ} \mathrm{C}$. Nonsaturable transport, measured in the presence of $2 \mathrm{mM}$ cold carnitine, was subtracted from total transport to obtain saturable carnitine transport. Data are means \pm SD of six observations. Carnitine transport by cells from the new patients reported in this study is shown on the right. The other patients were previously reported.6,11,12,16 Carnitine transport by the patients' cells was always significantly different $(P<0.01$, using analysis of variance) from that of the control group (note the broken scale on the $\mathrm{Y}$ axis).
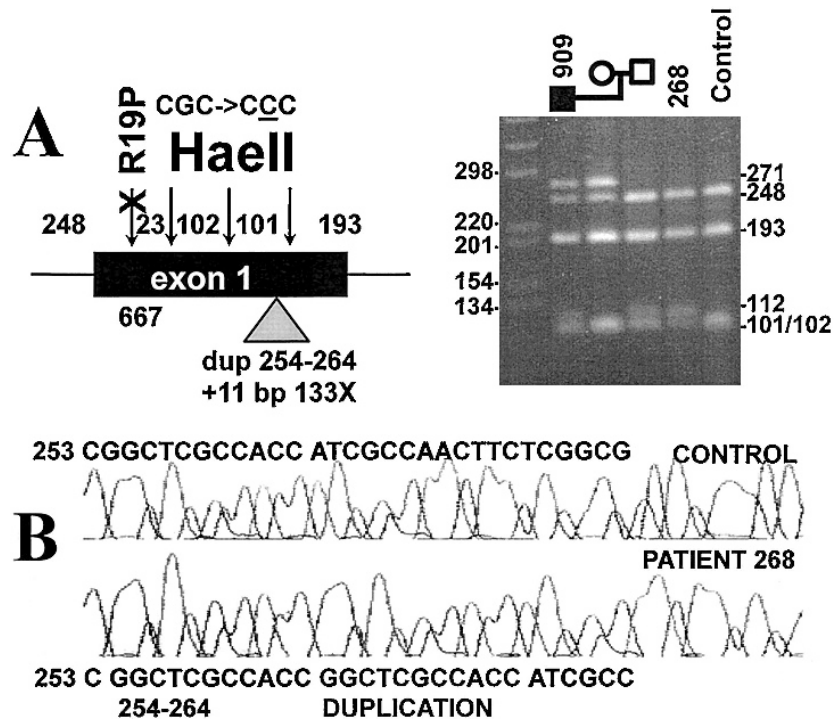

Fig. 2 R19P and dup 254-264, +11 bp, 133X mutations in the SLC22A5 gene in Patients 268 and 909 with primary carnitine deficiency. The R19P mutation (A) abolished a HaeII restriction site in exon 1, resulting in an undigested fragment of $271 \mathrm{bp}$. Patient 909 and his mother were heterozygous for this mutation. The 11-bp duplication resulted in a novel fragment of 112 bp. Patient 909 and his father were heterozygous for this mutation. Patient 268 was homozygous for this mutation, and direct sequencing of exon 1 revealed only the sequence with the 11-bp duplication (B).

resulting in the appearance of an undigested band of $271 \mathrm{bp}$. The patient inherited the R19P mutation from his mother, while the dup 254-264/133X mutation was inherited from his father.

Patient JGSQ was homozygous for a $12 \mathrm{C}>\mathrm{G}$ transversion in exon 1, converting the codon for Tyr 4 to a STOP codon (Y4X, Fig. 3A). This mutation inserted a novel $B f a I$ restriction site. $B f a I$ digestion of PCR-amplified exon 1 from Patient JGSQ generated two bands of 464 and $203 \mathrm{bp}$, compared with the normal band of $667 \mathrm{bp}$. Both parents were heterozygous for this mutation as was the unaffected sister. A healthy brother did not carry the Y4X mutation.

Patients Jer-T and Jer-H were homozygous for a 1196G $>$ A transition in exon 7, converting the codon for Arg 399 to Gln (R399Q, Fig. 3B). The R399Q mutation abolished an MspI restriction site in exon 7. After digestion with MspI, the PCRamplified exon 4 of Patients Jer-T and Jer-H had a single band $334 \mathrm{bp}$, compared with the normal bands of 195 and $139 \mathrm{bp}$. Both parents were heterozygous for this mutations and had bands of 334, 195, and $139 \mathrm{bp}$. Southern blot analysis of DNA from Patients 268, 909, JGSQ, and Jer-T failed to identify abnormal bands (data not shown).

\section{Effect of OCTN2 mutations on mRNA levels}

Two of the mutations identified caused the premature insertion of a STOP codon either as a result of a single nucleotide change (Y4X) or as a result of a frameshift (dup 254-264, 133X). The premature insertion of a STOP codon can produce a truncated protein, result in unstable RNA, or cause exon skipping. In cells from two previous patients (2996 and 10665) with primary carnitine deficiency caused by premature STOP 

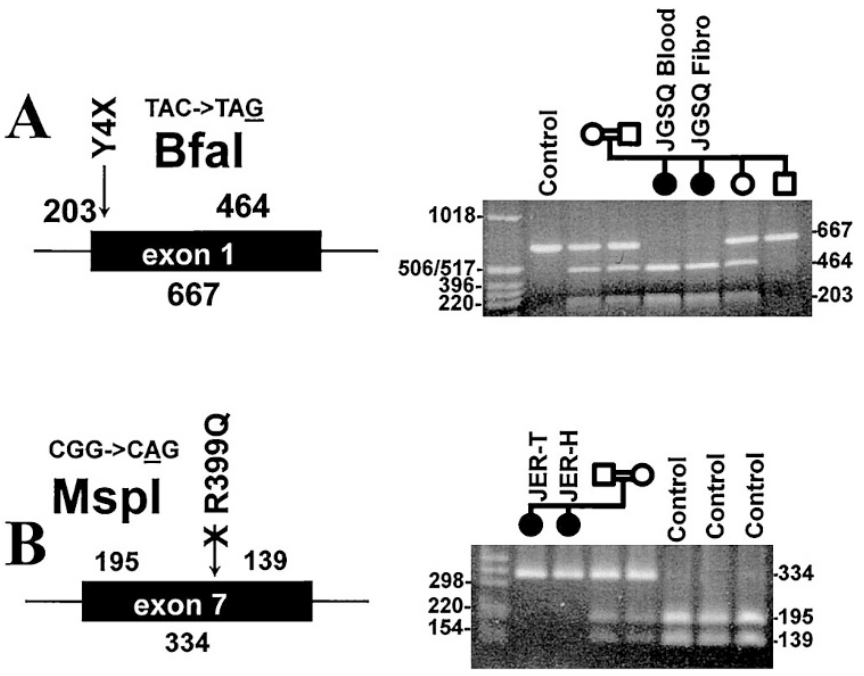

Fig. 3 Y4X and R399Q mutations in the SLC22A5 gene in patients with primary carnitine deficiency. The Y $4 \mathrm{X}$ mutation created an additional $B f a \mathrm{I}$ site in exon 1, resulting in the appearance of novel 464- and 203-bp bands after restriction analysis (A). DNA from Patient JGSQ obtained from fibroblasts and blood was homozygous for this mutation. DNA from both parents and one sister was heterozygous for this mutation, while one brother was homozygous normal. The R399Q mutation abolished an MspI restriction site in exon 7, causing the presence of an undigested fragment of $334 \mathrm{bp}$ (B). Patients Jer- $\mathrm{H}$ and Jer-T were homozygous for this mutation, while both related parents were heterozygous. codons, we demonstrated markedly reduced OCTN2 mRNA levels by RNAse protection assay. ${ }^{6}$ Northern blot analysis of poly $(\mathrm{A})^{+}$RNA from one of these previous patients (10665), used as a positive control, and our new patients with carnitine deficiency is shown in Figure 4. OCTN2 mRNA levels were markedly decreased in cells from Patients 10665, JGSQ, and 268, while they were normal in cells from Patient Jer-H.

Although the levels of OCTN2 mRNA in fibroblasts from Patient 909 appeared reduced, it was unclear whether this finding was significant in view of the variations in OCTN2 mRNA levels among control cells. Patient 909 is compound heterozygous for a missense (R19P) and a nonsense (dup 254-264, 133X) mutation. The two alleles should have similar levels of expression if the premature STOP codon did not affect RNA stability. To test this, reverse transcriptase (RT)-PCR products of the region containing the two mutations were digested with HaeII. The R19P mutation resulted in the appearance of a novel 123-bp band, while the dup 254-264, 133X created a novel band of $112 \mathrm{bp}$. As seen in Figure 4, only the 123-bp band was evident in RNA from Patient 909. Because RT-PCR is more sensitive than Northern blot analysis, bands could be seen even for cells of Patient 268. As expected, only the 112-bp band was present in RNA from Patient 268, consistent with homozygosity for the dup 254-264, 133X mutation. Therefore, it appears that only the R19P allele had significant levels of
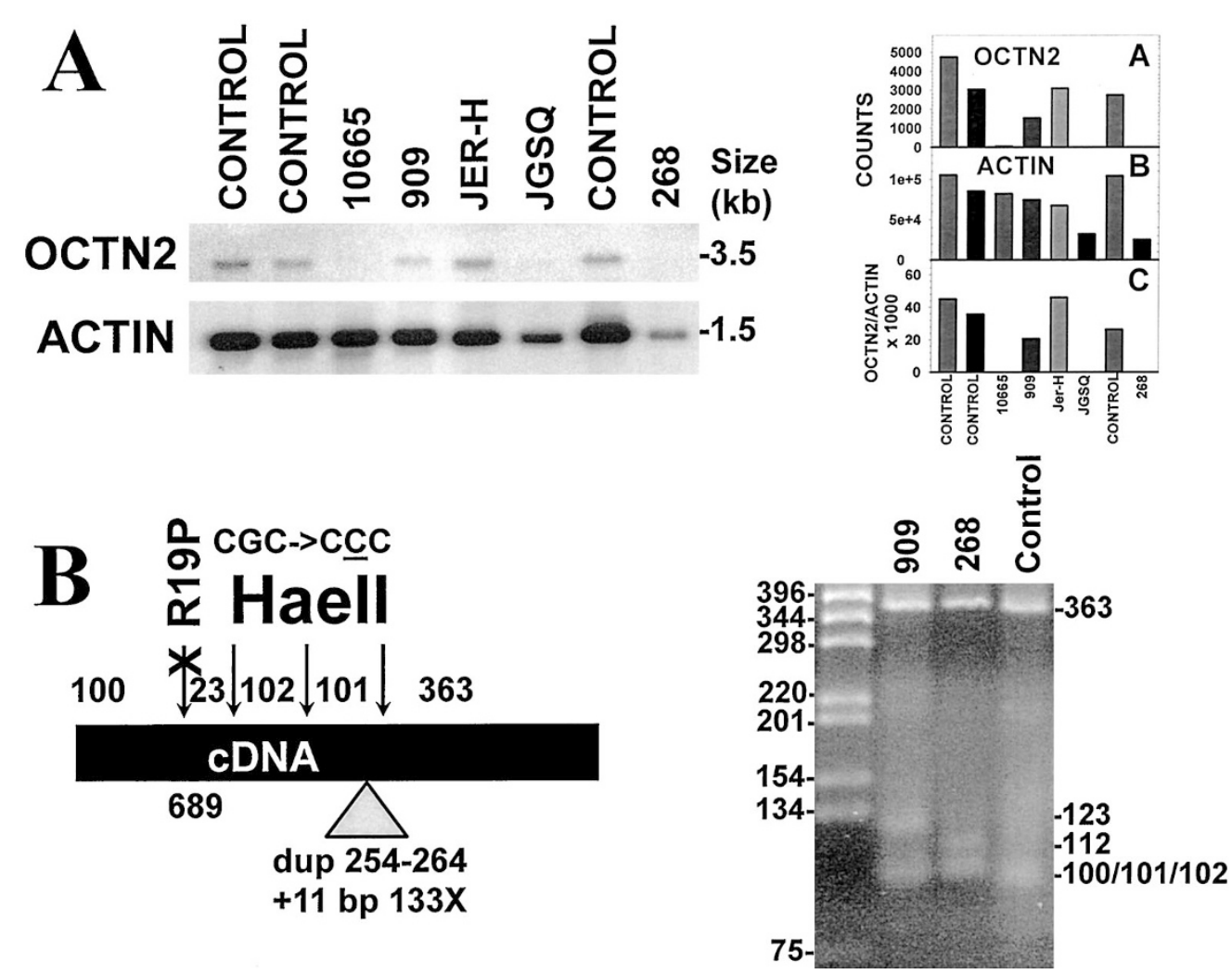

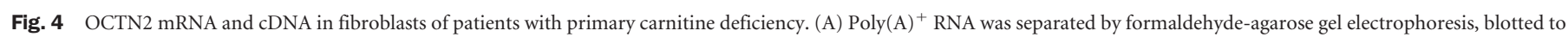

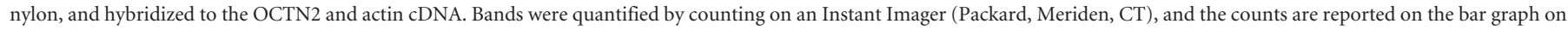

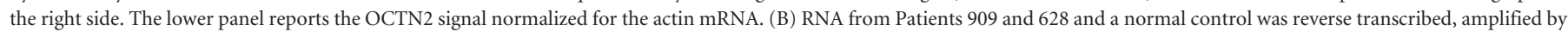

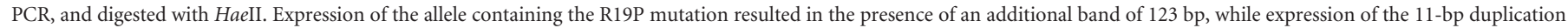
resulted in an additional band of $112 \mathrm{bp}$. Note the exclusive presence of the R19P allele in RNA from Patient 909. 
mature RNA in cells from Patient 909. These results indicate that the major effect of the premature insertion of STOP codons (Y4X and 133X) was a decrease in the levels of mature OCTN2 mRNA.

\section{Expression of mutant OCTN2 cDNAs in mammalian cells}

To confirm their causative role, the R19P and R399Q mutations were created by site-directed mutagenesis in a mammalian expression vector and transfected into $\mathrm{CHO}$ cells (Fig. 5). Expression of the transfected cDNA was verified by the appearance of green fluorescence in transfected cells. ${ }^{15}$ Both mutations produced markedly reduced carnitine transport compared with the wild-type OCTN2 when stably transfected into $\mathrm{CHO}$ cells. Analysis of multiple clones indicated that cells expressing the R19P- and R399Q-mutant OCTN2 transporter had residual carnitine transport activity, which, in different experiments, was 3\% to $5 \%$ of that of the normal OCTN2 cDNA. This residual transport activity is in the range previously measured with the A301D and E452K mutations in OCTN2. ${ }^{11,12,15}$

\section{DISCUSSION}

Primary carnitine deficiency is an autosomal recessive disorder of fatty acid oxidation that can present at different ages with hypoketotic hypoglycemia and cardiomyopathy and/or skeletal myopathy. This disease is suspected based on reduced levels of carnitine in plasma and confirmed by measurement of carnitine transport in the patient's fibroblasts. Carnitine transport was markedly reduced $(<5 \%$ of normal) in fibroblasts obtained from all our new patients with primary carnitine deficiency (Fig. 1).

Molecular analysis revealed four novel mutations in the OCTN2 carnitine transporter (Figs. 2, 3). Two mutations (Y4X

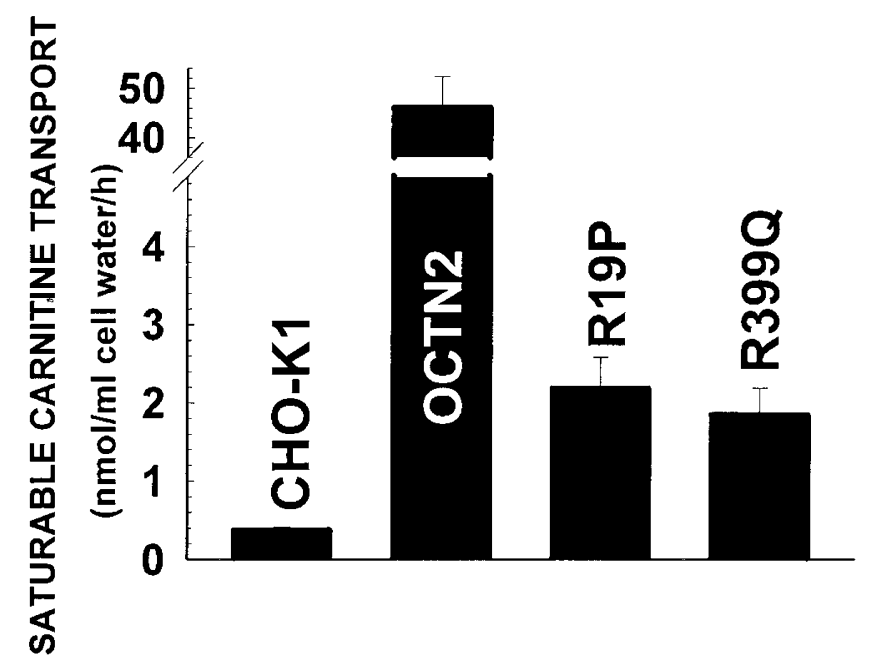

Fig. 5 Expression of normal and mutant OCTN2 cDNA in CHO cells. CHO cells were stably transfected with the OCTN2 cDNA cloned in pEGFP. After selection for resistance to $\mathrm{G} 418(0.8 \mathrm{mg} / \mathrm{mL})$, expression of the trans-gene was verified by fluorescent microscopy. Carnitine $(0.5 \mu \mathrm{M})$ transport was measured for 1 hour and corrected for nonsaturable uptake (measured in the presence of $2 \mathrm{mM}$ cold carnitine). Points are averages \pm SD of nine samples. and $133 \mathrm{X}$ ) resulted in the premature insertion of STOP codons and reduced OCTN2 mRNA levels (Fig. 4). Two missense mutations (R19P and R399Q) retained minimal residual transport activity when expressed in $\mathrm{CHO}$ cells (Fig. 5). When data from cultured fibroblasts were re-analyzed from the perspective of the mutations identified, cells from patients homozygous or compound heterozygous for missense mutations (Patients 255,430,669,909,1003, Balt-1, Jer-T, Jer-H) had higher residual carnitine transport $(80 \pm 30 \mathrm{pmol} / \mathrm{mL}$ cell water/h) than cells from patients homozygous or compound heterozygous for nonsense mutations (Patients 268, 2996, 10665, JGSQ, $8 \pm$ $4 \mathrm{pmol} / \mathrm{mL}$ cell water $/ \mathrm{h}, P<0.01$ vs. transport in fibroblasts with missense mutations using analysis of variance).

Residual transport activity had no clear effect on the phenotype, and we have previously reported that there is no definite correlation between genotype and phenotype in primary carnitine deficiency. ${ }^{12}$ The findings reported in this study confirm and extend this observation. The phenotype and age of onset was similar among the reported patients, irrespective of the type of mutation (missense or nonsense) identified. Different types of presentation have been observed within an individual family. ${ }^{17}$ In family Jer, two affected siblings homozygous for the R399Q mutation presented either early in life with hypoglycemic coma or with mild delays later in life. To our knowledge, this is the first time that a child with this disorder has presented with isolated developmental delays. Therefore, primary carnitine deficiency and testing for plasma carnitine levels might be considered in the differential diagnosis for developmental delays.

The new mutations identified expand the list of natural alterations in the OCTN2 carnitine transporter (Fig. 6). Based on the currently accepted model for the OCTN2 carnitine transporter, ${ }^{3,4}$ the novel missense mutations (R19P and R399Q) are located in intracellular domains of the protein with no recognized function. Preliminary experiments indicate that they do not affect recognition of sodium or carnitine (Wang Y., Longo N., unpublished results), and further studies are required to define the specific mechanism by which they impair carnitine transport. Natural mutations have now been identified in most regions of the OCTN2 transporter, but no missense mutation has yet been identified in the predicted extracellular portion of this transmembrane protein. It is unclear if this is due to the limited number of patients examined at a molecular level, or to the fact that variations in the extracellular domain have limited functional significance, or perhaps because the phenotype produced by extracellular mutations differs from the classic phenotype, with patients escaping ascertainment. The study of additional families and mutagenesis of the extracellular domains of this transporter should clarify this point.

Although most families have private mutations, some mutations have been reported more than once. A few mutations have been reported in distinct populations. ${ }^{6,8,9}$ These mutations likely occur at mutation-prone DNA sequences, ${ }^{12}$ because they have occurred on different haplotypes. ${ }^{8}$ In other cases, the same mutation recurs in patients with similar genetic backgrounds. The 11-bp deletion in exon 1 was found in two unrelated patients originating from Switzerland and neighbor- 


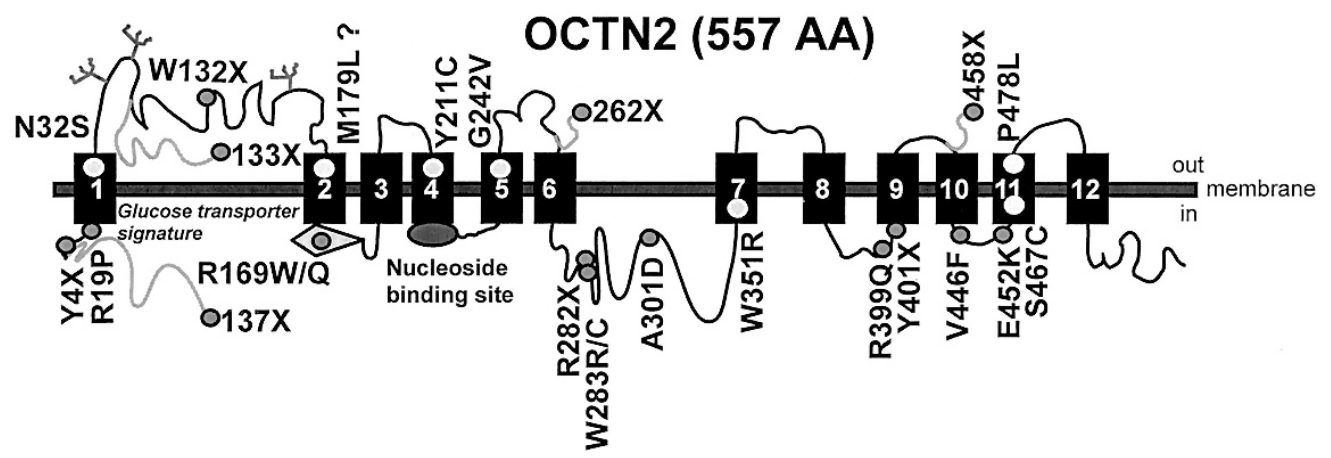

Fig. 6 Mutations in the OCTN2 carnitine transporter in primary carnitine deficiency. The encoded membrane protein is composed of 557 amino acids. Hydropathy analysis suggests that the transporter forms 12 transmembrane spanning domains (rectangles) with both the $\mathrm{N}$ - and C-termini facing the cytoplasm. Putative glycosylation sites are indicated by branching, the glucose transporter signature by a rhomboid, and the nucleoside binding site by an oval. Mutations identified in patients with primary carnitine deficiency are indicated by circles. The neo-sequences produced by frameshift mutations are indicated by gray lines before the premature STOP codon. The M179L substitution has a question mark because it does not impair carnitine transport when expressed in $\mathrm{CHO}$ cells. ${ }^{18}$

ing Northern Italy. In our previous study, the R169W mutation was identified in two unrelated Italian families. ${ }^{12}$ In addition, there is an unusually high frequency of homozygosity for mutations in the SLC22A5 gene in families of patients with primary carnitine deficiency and no known consanguinity, ${ }^{6,9,12-14}$ including a new patient (Patient 268) reported in this study. A similar phenomenon was observed in the Akita prefecture in Japan, where most families have a combination of a few mutations, ${ }^{18}$ a phenomenon attributed to a founder effect and to the social and geographical isolation of the island. In the case of our European patients, it is possible that some of the mutations recurring more than once are very old and could have spread to neighboring geographical areas. The consanguinity detected could be random and due to the limited mobility of families in relatively small geographical areas. With the mutations reported here, five different mutations (R19P, 133X, R169W, A301D, and W351R) have been detected in five different families in a relatively small geographical area consisting of Northern Italy and neighboring Switzerland. This finding suggests that additional mutations may be present in other families with primary carnitine deficiency from the same geographical area and that DNA screening would identify only a portion of patients at risk for this disease.

\section{Acknowledgments}

Supported in part by grant DK 53824 from the National Institutes of Health.

\section{References}

1. Scaglia F, Longo N. Primary and secondary alterations of neonatal carnitine metabolism. Semin Perinatol 1999;23:152-161.

2. Wilcken B, Wiley V, Sim KG, Carpenter K. Carnitine transporter defect diagnosed by newborn screening with electrospray tandem mass spectrometry. J Pediatr 2001; 138:581-584.

3. Wu X, Prasad PD, Leibach FH, Ganapathy V. cDNA sequence, transport function, and genomic organization of human OCTN2, a new member of the organic cation transporter family. Biochem Biophys Res Commun 1998;246:589-595.

4. Tamai I, Ohashi R, Nezu J, Yabuuchi H, Oku A, Shimane M, Sai Y, Tsuji A. Molecular and functional identification of sodium ion-dependent, high affinity human carnitine trans-porter OCTN2. J Biol Chem 1998;273:20378-20382.
5. Nezu J, Tamai I, Oku A, Ohashi R, Yabuuchi H, Hashimoto N, Nikaido H, Sai Y, Koizumi A, Shoji Y, Takada G, Matsuishi T, Yoshino M, Kato H, Ohura T, Tsujimoto G, Hayakawa J, Shimane M, Tsuji A. Primary systemic carnitine deficiency is caused by mutations in a gene encoding sodium ion-dependent carnitine transporter. Nat Genet 1999;21:91-94.

6. Wang Y, Ye J, Ganapathy V, Longo N. Mutations in the organic cation/carnitine transporter OCTN2 in primary carnitine deficiency. Proc Natl Acad Sci U S A 1999; 96:2356-2360

7. Tang NL, Ganapathy V, Wu X, Hui J, Seth P, Yuen PM, Wanders RJ, Fok TF, Hjelm NM. Mutations of OCTN2, an organic cation/carnitine transporter, lead to deficient cellular carnitine uptake in primary carnitine deficiency. Hum Mol Genet 1999;8:655-660.

8. Burwinkel B, Kreuder J, Schweitzer S, Vorgerd M, Gempel K, Gerbitz KD, Kilimann MW. Carnitine transporter OCTN2 mutations in systemic primary carnitine deficiency: a novel Arg169Gln mutation and a recurrent Arg282ter mutation associated with an unconventional splicing abnormality. Biochem Biophys Res Commun 1999; 161:484-487.

9. Vaz FM, Scholte HR, Ruiter J, Hussaarts-Odijk LM, Pereira RR, Schweitzer S, de Klerk JB, Waterham HR, Wanders RJ. Identification of two novel mutations in OCTN2 of three patients with systemic carnitine deficiency. Hum Genet 1999;105: 157-161.

10. Mayatepek E, Nezu J, Tamai I, Oku A, Katsura M, Shimane M, Tsuji A. Two novel missense mutations of the OCTN2 gene (W283R and V446F) in a patient with primary systemic carnitine deficiency. Hum Mutat 2000;15:118.

11. Wang Y, Kelly MA, Cowan TM, Longo N. A missense mutation in the OCTN2 gene associated with residual carnitine transport activity. Hum Mutat 2000;15:238-245.

12. Wang Y, Taroni F, Garavaglia B, Longo N. Functional analysis of mutations in the OCTN2 transporter causing primary carnitine deficiency: lack of genotype-phenotype correlation. Hum Mutat 2000;16:401-407.

13. Cederbaum S, Dipple K, Vilain E, Miller M, Koo-McCoy S, Hsu BYL, Ganguly A, Stanley C. Clinical follow-up and molecular etiology of the original case of carnitine transporter deficiency. J Inherit Metab Dis 2000;23(suppl 1):119.

14. Christensen E, Holm J, Hansen SH, Sorensen N, Nezu J, Tsuji A, Skovby F. Sudden infant death following pivampicillin treatment in a patient with carnitine transporter deficiency. J Inherit Metab Dis 2000;23(suppl 1):117.

15. Wang Y, Meadows TA, Longo N. Abnormal sodium stimulation of carnitine transport in primary carnitine deficiency. J Biol Chem 2000;275:20782-20786.

16. Scaglia F, Wang Y, Singh RH, Dembure PP, Pasquali M, Fernhoff PM, Longo N. Defective urinary carnitine transport in heterozygotes for primary carnitine deficiency. Genet Med 1998;1:34-39.

17. Stanley CA, DeLeeuw S, Coates PM, Vianey-Liaud C, Divry P, Bonnefont JP, Saudubray JM, Haymond M, Trefz FK, Breningstall GN, Wappner RS, Byrd DJ, Sansariq C, Tein I, Grover W, Valle D, Rutledge SL, Treem WR. Chronic cardiomyopathy and weakness or acute coma in children with a defect in carnitine uptake. Ann Neurol 1991;30:709-716.

18. Koizumi A, Nozaki J, Ohura T, Kayo T, Wada Y, Nezu J, Ohashi R, Tamai I, Shoji Y, Takada G, Kibira S, Matsuishi T, Tsuji A. Genetic epidemiology of the carnitine transporter OCTN2 gene in a Japanese population and phenotypic characterization in Japanese pedigrees with primary systemic carnitine deficiency. Hum Mol Genet 1999;8:2247-2254. 